\title{
Changes in Lipid Oxidation of Reconstituted Omega-3 Plus Milk Powder Treated by Superheated Steam
}

\author{
Ghazwan Mahdy *1 , Tajul A. Yang ${ }^{* 2}$ \\ \# Department of Food Science, School of Agricultural, University of Tikrit, Tikrit Salah Al-Ddin, Iraq \\ E-mail: ' gazwanmahdy@yahoo.com
}

\author{
* Food Technology Division, School of Industrial Technology, University Sains Malaysia, Minden 11800 Pulau Pinang Malaysia
} E-mail: ${ }^{2}$ taris@usm.my

\begin{abstract}
In this study the effect of superheated steam on the oxidative stability of reconstituted omega-3plus milk powder was studied. The changes in fatty acids, peroxide, acids, thiobarbutric acid reactive substances (TBARS), and p-anisidine values were measured to reconstitute omega-3 plus milk powder in relation to thermal treatment by using a superheated steam (SHS) with different temperatures and time periods. The temperature and time period ranged from 120-180 ${ }^{\circ} \mathrm{C}$ between 5-15 min. For applying the SHS treatment did not produce changes in SFA, MUFA and PUFA at 120-150 ${ }^{\circ} \mathrm{C}$ to $10-15$ min as compared with the control. While, the proportion of PUFA and MUFA values were recorded differences on temperature $180{ }^{\circ} \mathrm{C}$ comparison with control. The result of POV showed no changes between the temperature 120-150 ${ }^{\circ} \mathrm{C}$ compared with control, but indicated significant differences at the temperature $180{ }^{\circ} \mathrm{C}$ with long time $15 \mathrm{~min}$. Acids and $\mathrm{p}$ - anisdine values did not show any differences between temperature 120 $180{ }^{\circ} \mathrm{C}$ for a short period of time $5 \mathrm{~min}$ compare with the control, but recorded significantly on long period of time 10-15 min compared with the control. The values of TBARS showed no significant differences in temperature 120-150 for 5 min compare with control. This study showed oxidative stability of milk fat supplied long chain unsaturated fatty acids treated by SHS on temperature range 120-150 at time 5-10 min with some affected by the high temperature $180{ }^{\circ} \mathrm{C}$ at 15 min can maintain the quality of fatty acid and milk fat.
\end{abstract}

Keywords - superheated steam, omega-3 plus milk powder, fatty acids, lipid oxidation

\section{INTRODUCTION}

The family of omega-3 polyunsaturated fatty acid (PUFA) consists of many types of polyunsaturated fatty acids such as $\alpha$-linolenic acid (C18:3), long-chain eicosapentaenoic acid (EPAC20:5) and docosahexaenoic acid (DHA C22: 6) [1]. The omega-3 fatty acids, especially long-chain of DHA and EPA polyunsaturated fatty acids are well known in the prevention of some types of cancer, rheumatoid arthritis and cardiovascular diseases. In Addition the DHA acts have important factor to ensuring proper development. and function of the brain.and a visual functionality [2,3]. Some Researchers have shown that diets rich of omega-3-fatty acids can reduce blood triglyceride levels and platelet aggregation and show both antithrombotic and antiinflammatory effects. [4,5]. Some health centers in the UK such as united kingdom's department of Health recommend to intake the long chain fatty acids (EPA and DHA) every week and estimated the ratio needed by $1.5 \mathrm{~g}$, and that approximately equivalent $0.2 \mathrm{~g}$ per day, also the (EANS) European Academy of Nutritional Sciences recommends 0.2 $\mathrm{g}$ of EPA and DHA as the average per day [6,7]. The FDA limit daily intake of DHA and EPA and remand should be not exceed $3 \mathrm{~g}$ per day to adult and can take this ratio from fish oil or any food fortified source [1]. Consumption long chain unsaturated fatty acids include DHA and EPA fortified of various food that's can be increase the omega-3 average intake and that can give better results of the health protection to consumers [8-10]. Milk powder is widely used for manufacturing foods such as cakes, pastries, and chocolates, that's because milk can improve food characteristics, including texture, color, and flavor [11]. Mean compound responsible on the flavoured and nutritional value is the fat, milk fat approximately consist triglycerides, which form $98 \%$, the $2 \%$ remaining are milk fat consists mainly of triglycerides, approximately $98 \%$, while other milk lipids are diacylglycerol, cholesterol, phospholipids and free fatty acids [12]. The milk fat is more complex of nutrition lipids and this is due to having about 400 fatty acids $[13,14]$. Milk fat has two types of fatty acids, saturated fatty acids consist $70 \%$ and unsaturated fatty acids consist $30 \%$, the most important of saturated fatty acids is palmitic acid its form 
approximately $30 \%$ of total fatty acids. Stearic acid and myristic acids mike up 11-12\% and short-chain fatty acids C4-C10 make $10.9 \%$ of saturated fatty acids, while the unsaturated fatty acids approximately consist $25 \%$ monounsaturated fatty acids oleic acid. The polyunsaturated fatty acids considered an important source of omega-3 fatty acids, which be lower in milk fat and must be fortified from another source $[13,15]$. Omega-3 and omega- 6 considered essential fatty that's due humans and animals cannot synthesize these fatty acids and must get them from other diets. Many diets are rich in omega- 3 and omega- 6 such as olive oil, flax seed and fish and the researcher's use these diets as a natural source for fortified omega-3 and omega- 6 to the other food [16]. Milk powder plus omega-3 and omega- 6 is widely use from the consumers because has high nutrition value coming by nutritive compounds of milk and omega-3 and omega- 6 fortified to it, some of reconstituted milk powder used as the addition product to the other food such as produce the biscuit, cake, pastries and chocolate all these products undergo to the high temperature during manufacturing and thus effect on the fatty acid especially omega-3 and omega- 6 because it's how many unsaturated bonds that are easy breakage during exposure to high temperature with present of oxygen $[17,18]$. The oxygen play means the role of degraded fatty acids, especially polyunsaturated fatty acids that's because after Break down the fatty acid bonds free radicals will formation, these free radicals, unstable which can attack with the oxygen to produce proxy radicals and this can be lead to form the hydroperoxides which considered mean compounds responsible on degraded fatty acids by oxygen [19].

About 100 years ago superheated steam was discovered, but it's not taking attention and development until 20 years ago and become more used in the energy applied. Superheated steam is a clear, colorless gas obtained by heating ordinary steam at $100^{\circ} \mathrm{C}$ to a higher temperature under normal pressure with its high heat transfer capabilities, it is applied to a wide range of industry that's returned to attributes of the features superiority of other energy sources [20]. Superheated steam has many applied in the industry and it's developed to be more benefits in dehydration and processing foods includes herbs, lumber, paper, coal, sugarbeet, pulp, tortilla, chips, shrimp, vegetables, potato and spices [21]. In the superheated steam there is no oxygen available during the drying or process like the other thermal methods such as hot air and that's mean there are no oxidative or combustion reactions will occur during the processing [22]. The aim of this study was investigating the effect of superheated steam on oxidative stability of reconstituted omega-3 plus milk powder on the fatty acids, POV, TBRS, Acid value and P-anisidine value.

\section{MATERIAL AND METHOD}

\section{A. Omega-3 plus milk powder}

Omega-3 plus milk powder were supplied by Nestle and purchased from Tesco in Penang, Malaysia. The standard amounts of whole milk powder contents were follows: fat (9.4 g per $100 \mathrm{~g})$, protein (20 g per $100 \mathrm{~g})$, carbohydrate (57 $\mathrm{g}$ per $100 \mathrm{~g})$.

\section{B. Milk powder reconstitution}

The reconstituted omega-3 plus milk powder was prepared according to the instructions of the manufacturer listed on the packages. The milk was reconstituted using 33 $\mathrm{g}$ of milk powder and adding $225 \mathrm{~mL}$ of water. The mixture was shaken on a magnetic stirrer for $10 \mathrm{~min}$.

\section{Heating reconstituted milk powder by superheated steam oven}

Thermal coefficient samples were exposed in a superheated steam oven after milk reconstitution and yielded a total of $500 \mathrm{ml}$ of samples. The collected samples exposed in a superheated steam oven (AX1500) were infectious. The samples were exposed at various temperatures $(120,150$ and $180^{\circ} \mathrm{C}$ ) and period times (5, 10, and $15 \mathrm{~min}$ ) all samples subsequently underwent analyses.

\section{Milk fat extraction}

Milk fat was extracted from the reconstituted omega-3 plus milk powder using the Folch 1957 method with some modification chloroform, methanol and water (2:1:1) 22 [23]. Percentage of solvent was 20, 10 and 10 respectively. The solvent mixture containing the extracted lipids was separated from the reconstituted milk by centrifugation. After that the mixture was mixed with $0.88 \%$ of $\mathrm{KCl}$ solution in a separating funnel with stirring vigorously for phase separation. The upper layer was separated these contain water and methanol and non-lipid and the lower phase was separated these layers contain the chloroform and lipid. This layer was filtration by Buchner funnel use anhydrous sodium sulfate. The residue was collected out in glass vials and the solvent was removed by use rotary evaporator with temperature bellow $50{ }^{\circ} \mathrm{C}$.

\section{E. Fatty acid analysis}

Fatty acids were acquired by trans ethylating into fatty acid methyl ester, which was carried out by [24]. Approximately $150 \mathrm{mg}$ of milk fat was added to $5.0 \mathrm{~mL} 0.25$ mol L-1 sodium methoxide in methanol-diethyl ether (1:1) and it was stirring vigorously for $3 \mathrm{~min}$. After that $3 \mathrm{~mL}$ of isooctane and $15 \mathrm{~mL}$ of saturated sodium chloride were added. The tube was stirring vigorously again and waiting after the phase separation. The upper layer was transferred to GC vial for analysis. $1 \mathrm{ml}$ of the upper layer was transferred to $1.5 \mathrm{ml} \mathrm{GC}$-glass. Fatty acids were identified by comparing the retention times of FAME mixture with those of standard purchased from Supelco (16823-0048) USA and is contained 37 fatty acids. The fatty acid composition of omega-3 milk powder was directly analyzed using Gas Chromatography (GC-FID) with SGE-BPX 70 column. The condition of GC during the analysis was set as follows: rates used were 1.4 $\mathrm{mL}$ min-1 carrier gas (H2), $30 \mathrm{~mL}$ min-1 make-up gas (N2), and 30 and $300 \mathrm{~mL}$ min-1 flame gases, $\mathrm{H} 2$ and flame synthetic air, respectively. The injection sample take rate $1 / 100$ with detector temperatures $235{ }^{\circ} \mathrm{C}$. The column temperature was $65^{\circ} \mathrm{C}$ for $4 \mathrm{~min}$, followed by a ramp of 16 ${ }^{\circ} \mathrm{C}$ min-1 up to $185{ }^{\circ} \mathrm{C}$, kept for $12 \mathrm{~min}$. A second ramp of $20^{\circ} \mathrm{C}$ min-1 was run up to $235^{\circ} \mathrm{C}$ for $14 \mathrm{~min}$. The total analysis time was $40 \mathrm{~min}$. 


\section{F. Lipid Oxidation analysis}

Peroxide value and acid value were determined according to AOCS official methods described by [25]. The thiobarbutric acid reactive substances (TBARS) of milk fat were evaluated using park method 1997 with some modifications. Approximately $2 \mathrm{~g}$ of milk was mixed with 2 $\mathrm{ml}$ of $20 \%$ trichloroacetic acid solution with $4 \mathrm{ml}$ of $0.01 \mathrm{M}$ TBA solution. Subsequently, the sample was heated in a water bath at $90{ }^{\circ} \mathrm{C}$ for $15 \mathrm{~min}$. The TBA solution with milk fat was cooled in an ice bath for 15 min. The solution of pyridine and isoamylalchohol (2:1) was mixed with the TBA solution and centrifuged at $2400 \mathrm{rpm}$ for $15 \mathrm{~min}$. The supernatant was separated, and absorbance in the spectrophotometer (UV mini- 240, Japan) at $550 \mathrm{~nm}$ was converted to the TBARS by using Eq. 1 .

TBARS $=$ absorbance $\times 100 \times(3 / 2)$

P-Anisidine value was determined using the method of [26]. The p-anisidine was dissolved in glacial acetic acid to make a $0.25 \mathrm{~g} / 100 \mathrm{ml}$ solution. The solvent used was isooctane. The test was conducted in triplicate for all samples. Up to $0.3 \mathrm{~g}$ of the milk fat samples were accurately weighed and placed into $25 \mathrm{ml}$ volumetric flasks and diluted with isooctane. Up to $5 \mathrm{ml}$ of the solution was pipetted into a test tube; $5 \mathrm{ml}$ of isooctane was added, followed by $1 \mathrm{ml}$ of the p-anisidine solution. The mixture was mixed thoroughly in the test tube. After $10 \mathrm{~min}$, the absorbance of the sample was measured using a spectrophotometer (UV mini-1240, Japan) with $350 \mathrm{~nm}$. Isooctane was used as the reagent blank. Glass corvettes were used for all absorbance measurements. The p-anisidine values were calculated using Eq. 2.

$\mathrm{P}-\mathrm{A} . \mathrm{V}=25 \times(1.2 \mathrm{As}-\mathrm{Ab}) / \mathrm{m}$

As is the absorbance of the sample; $\mathrm{Ab}$ is the absorbance of blank; and $\mathrm{m}$ is the mass of fat.

\section{G. Statistical analysis}

The experiments were performed in triplicate, and the data were analyzed using SPSS version 20-2013 (SPSS Inc., Chicago, USA). Analysis of variance was performed, and Duncan's multiple range tests was used to compare significant differences $(\mathrm{p}<0.05)$.

\section{RESULT AND DISCUSSION}

\section{A. Changes in fatty acid composition during superheated steam heat treatment}

Fatty acid composition of reconstituted omega-3 plus milk powder that was heated in superheated steam oven on different temperature and periods of time shown in Table 1. The SFA is present in higher concentration of fatty acids in milk fat and the palmitic acid ( C16:0 ) recorded the highest value in saturated fatty acids. The PUFA was present the second values after SFA and that return to fortify the Omega-3 and Omega-6 fatty acids to this type of milk sample and $\alpha$ - linoleic acid (C18: $3 n-3)$ is the dominated on the PUFA. Linoleic acid (C18: $2 n-6)$ is second fatty acids dominated in the PUFA and its present omega -6 fatty acids in milk fat. At various heat treatment of superheated steam the fatty acids present no significant differences on temperature $120-150{ }^{\circ} \mathrm{C}$ in time $15-10 \mathrm{~min}$, respectively to the SFA, MUFA and PUFA with slight difference on the high temperature $180{ }^{\circ} \mathrm{C}$ for $5 \mathrm{~min}$. Table 1 present the amount of SFA, MUFA and PUFA to reconstituted omega 36 plus milk powder treated by superheated steam oven. Whilst, the Valuable of SFA, MUFA and PUFA were indicate decrease, but significantly did not show any differences compare with the control (sample without heating).

TABLE I

FATTY ACID COMPOSITION (MG. G-1) OF RECONSTITUTED OMEGA-3 PLUS MILK POWDER TREATED WITH SUPERHEATED STEAM.

\begin{tabular}{|c|c|c|c|c|}
\hline \multirow{2}{*}{$\begin{array}{c}\text { Fatty } \\
\text { acids (mg. } \\
\left.\mathrm{g}^{-1}\right)\end{array}$} & \multirow[t]{2}{*}{ Control } & \multicolumn{3}{|c|}{$\begin{array}{l}\text { Superheated } \\
\text { steam }\end{array}$} \\
\hline & & $\begin{array}{l}120^{\circ} \mathrm{C}, 15 \\
\min \end{array}$ & $\begin{array}{l}150^{\circ} \mathrm{C}, 10 \\
\min \end{array}$ & $\begin{array}{l}180^{\circ} \mathrm{C}, 5 \\
\min \end{array}$ \\
\hline $\mathrm{C} 8: 0$ & $10.18 \pm 0.31^{\mathrm{a}}$ & $10.06 \pm 0.13^{\mathrm{a}}$ & $10.02 \pm 0.13^{\mathrm{a}}$ & $9.80 \pm 0.10^{\mathrm{a}}$ \\
\hline C10:0 & $5.58 \pm 1.00^{\mathrm{a}}$ & $4.41 \pm 0.87^{\mathrm{a}}$ & $4.97 \pm 0.86^{\mathrm{a}}$ & $5.19 \pm 0.92^{\mathrm{a}}$ \\
\hline C12:0 & $27.81 \pm 1.15^{\mathrm{a}}$ & $27.76 \pm 0.05^{\mathrm{a}}$ & $27.43 \pm 0.48^{\mathrm{a}}$ & $27.02 \pm 0.06^{\mathrm{a}}$ \\
\hline C14:1 & $8.19 \pm 0.42^{\mathrm{a}}$ & $7.83 \pm 0.30^{\mathrm{a}}$ & $7.78 \pm 0.04^{\mathrm{a}}$ & $7.18 \pm 0.03^{\mathrm{b}}$ \\
\hline C16:0 & $116.37 \pm 1.22^{\mathrm{a}}$ & $116.05 \pm 0.59^{\mathrm{a}}$ & $115.94 \pm 2.61^{\mathrm{a}}$ & $108.43 \pm 1.02^{b}$ \\
\hline C18:0 & $10.25 \pm 0.64^{\mathrm{a}}$ & $10.31 \pm 0.35^{\mathrm{a}}$ & $9.47 \pm 0.39^{\mathrm{a}}$ & $9.41 \pm 0.28^{\mathrm{a}}$ \\
\hline C18:1n9 & $31.39 \pm 2.09^{\mathrm{a}}$ & $31.08 \pm 1.01^{\mathrm{a}}$ & $30.08 \pm 0.68^{\mathrm{a}}$ & $30.28 \pm 0.53^{\mathrm{a}}$ \\
\hline C18:2n6 & $33.83 \pm 5.14^{\mathrm{a}}$ & $33.44 \pm 5.34^{\mathrm{a}}$ & $32.25 \pm 13.02^{\mathrm{a}}$ & $32.64 \pm 9.29^{b}$ \\
\hline C18:3n 3 & $38.13 \pm 0.82^{\mathrm{a}}$ & $37.99 \pm 0.63^{\mathrm{a}}$ & $37.46 \pm 0.40^{\mathrm{a}}$ & $36.84 \pm 0.40^{\mathrm{a}}$ \\
\hline C20:0 & $9.54 \pm 0.67^{\mathrm{a}}$ & $9.56 \pm 0.99^{\mathrm{a}}$ & $9.16 \pm 0.75^{\mathrm{a}}$ & $9.28 \pm 0.67^{\mathrm{a}}$ \\
\hline $\begin{array}{l}\text { C20: } 5 \\
\text { (n3) EPA }\end{array}$ & $2.75 \pm 0.24^{\mathrm{a}}$ & $2.47 \pm 0.24^{\mathrm{a}}$ & $2.69 \pm 0.06^{\mathrm{a}}$ & $2.64 \pm 0.30^{\mathrm{a}}$ \\
\hline $\begin{array}{l}\text { C22: } 6 \\
\text { (n3) DHA }\end{array}$ & $4.18 \pm 0.43^{\mathrm{a}}$ & $4.16 \pm 0.41^{\mathrm{a}}$ & $3.76 \pm 0.99^{\mathrm{a}}$ & $3.70 \pm 1.03^{\mathrm{a}}$ \\
\hline$\sum$ SFA $^{*}$ & 179.73 & 178.15 & 176.99 & 169.13 \\
\hline$\sum$ MUFA $^{* *}$ & 39.58 & 38.09 & 37.86 & 37.46 \\
\hline$\sum$ PUFA $^{\text {**** }}$ & 77.89 & 77.06 & 71.16 & 68.82 \\
\hline
\end{tabular}

${ }^{\mathrm{a}-\mathrm{d}}$ Average with different letters in the same row indicate significant differences $(\mathrm{p}<0.05)$.

${ }^{*}$ SFA: saturated fatty acids.

** MUFA: monounsaturated fatty acids.

${ }^{* * *}$ PUFA: poly unsaturated fatty acids

Generally the fatty acids take decrease when treated with heat treatment [27]. Decrease the unsaturated fatty acid in milk treated with heat treatment due to the lipid oxidation initiated by the oxygen therefor, the superheated steam has free oxygen that due dry steam and can limit the oxidation and degradation fatty acids [28,29]. From the other hand, milk and milk product undergo to the convention heat treatment during preparation (microwave, boiling and cooking) and that's lead to undesirable changes in lipids and fatty acids by the oxidation steps that's leads to produce low molecule weight of products (aldehydes, ketones and lactones) which responsible on undesirable flavored in milk and milk products [11]. Microwave heat treatment recorded effect on the fat oxidation and fatty acids and isomer changes [30]. Interpretation of probability in the most nondegradation of fatty acids in milk treated by superheated steam that's the SHS work without present of oxygen with this advantage can prevent or reduce the oxidation process resulting maintains the fatty acids from degradation to increase the nutrition values of the products [31]. 


\section{B. Effect superheated steam on Lipid Oxidation of reconstituted omega-3-6 plus milk}

The effect of superheated steam on the acid value, Peroxide oxidation value (POV), p-Anisidine value and TBRS value of reconstituted omega3-6 plus milk were determined and the results show in fig 1, 2 and 3 .

Fig 1 show affects SHS temperatures and periods of time on the acid value. The results indicate no significant differences at the $120-180{ }^{\circ} \mathrm{C}$ for 5 min compare with the control. Among SHS heat treatment results recorded no significant differences between $120-180{ }^{\circ} \mathrm{C}$ but there are significant differences compared with the control at periods of time 10-15 min. All the results of acid value have not much changes from the control (sample without heating) even after long time, SHS has given good results of acid value from these treated by pasteurization or UHT process [32]. Increase the acid value in the samples indication to increase the free fatty acids in milk sample and that Interpretation of degradation lipids specially unsaturated fatty acids and reduce quality of products [33].

Effect SHS on the POV shown in fig 2. POV is a free radical chain produce from reaction between free radicals and the oxygen described in the initiation and propagation steps of oxidation. The Oxygen species play the mean rolls to produce the hydroperoxides by the free radicals and the hydrogen abstract [34]. SHS heat treatment indicates no significant differences between an SHS heat treat and the control (sample without heating). In this results the peroxide value ranged between $(6.66-8.00 \mathrm{meq} / \mathrm{kg}$ ) were below 25 meq of active $\mathrm{O} 2 / \mathrm{kg}$ which considered as limit of acceptability in the food [22]. Luck of POV in the SHS may explain that oxygen inside SHS which prevent or minimizes and that limited the lipid oxidation in the samples [29].

Effect SHS on the TBARS shown in fig 3. The results show no significant differences between SHS heat treatment, but indicate significant differences with the control. Heat treatment temperature 120,150 and $180 \mathrm{C}$ show stability of TBRS on parodies of time 5-10 min with slight changes on the long time $15 \mathrm{~min}$. TBARS is measure secondary lipid oxidation by reacting TBA thiobarbituric acid with alkenals and alkadienals resulting from secondary oxidation specially from unsaturated fatty acids more than 3 double bounds to give term of also react thiobarbituric acid reactive substances (TBARS) [35].

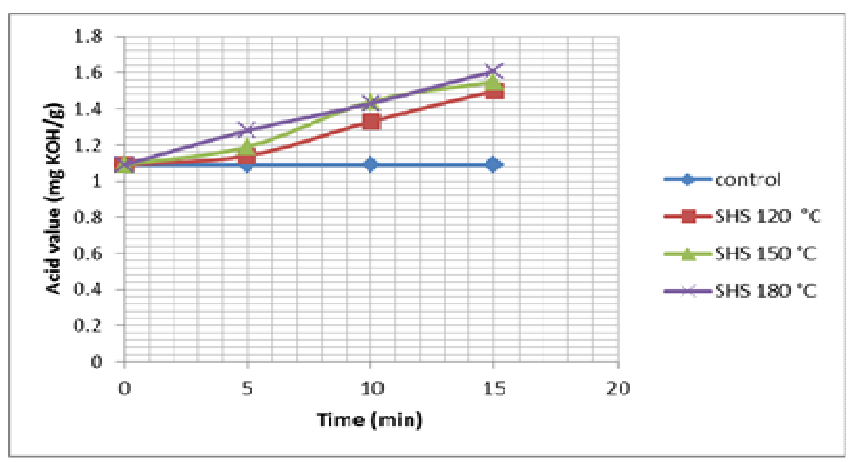

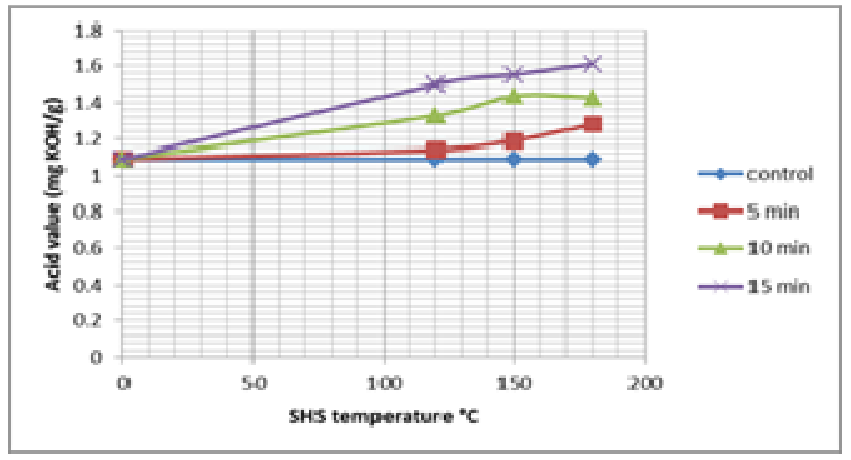

Figure 1: Effect superheated steam (temperature and time) on the acid value to reconstituted omega3-6 plus milk powder.
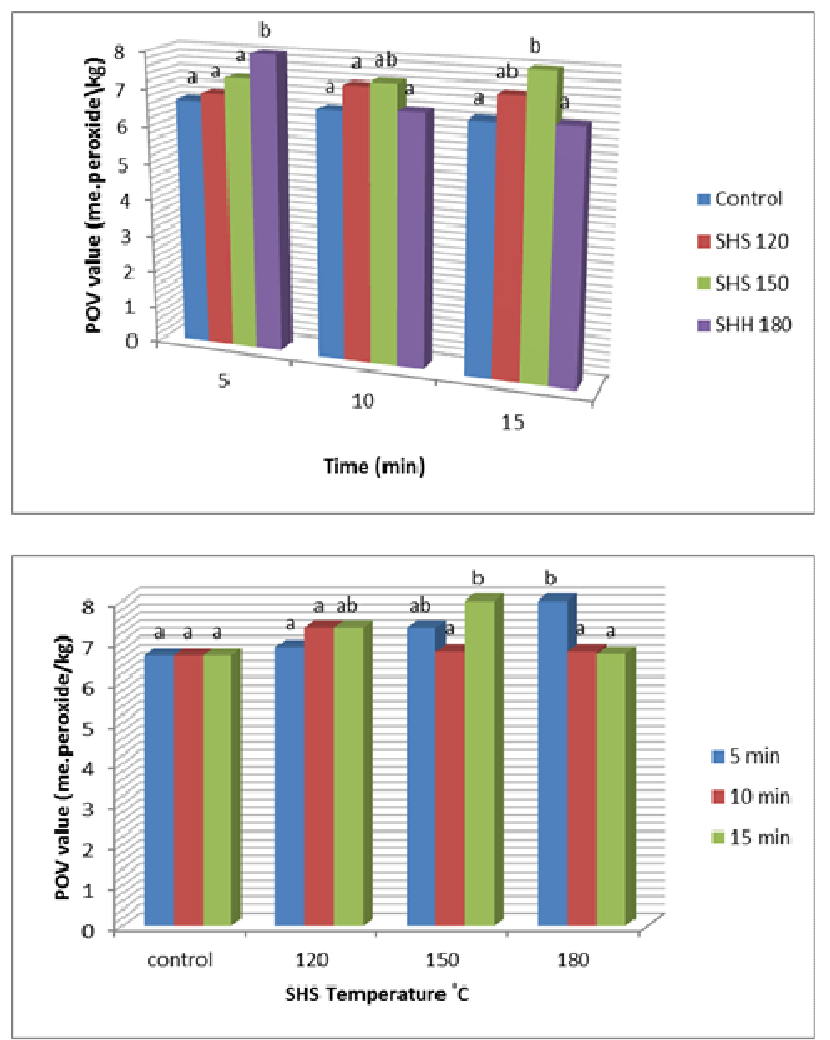

Fig 2: Effect superheated steam (temperature and time) on the POV value to reconstituted omega3-6 plus milk powder.

Effect SHS on the TBARS shown in fig 3. The results show no significant differences between SHS heat treatment but indicate significant differences with the control. Heat treatment temperature 120,150 and $180 \mathrm{C}$ show stability of TBRS on parodies of time 5-10 min with slight changes on the long time $15 \mathrm{~min}$. 

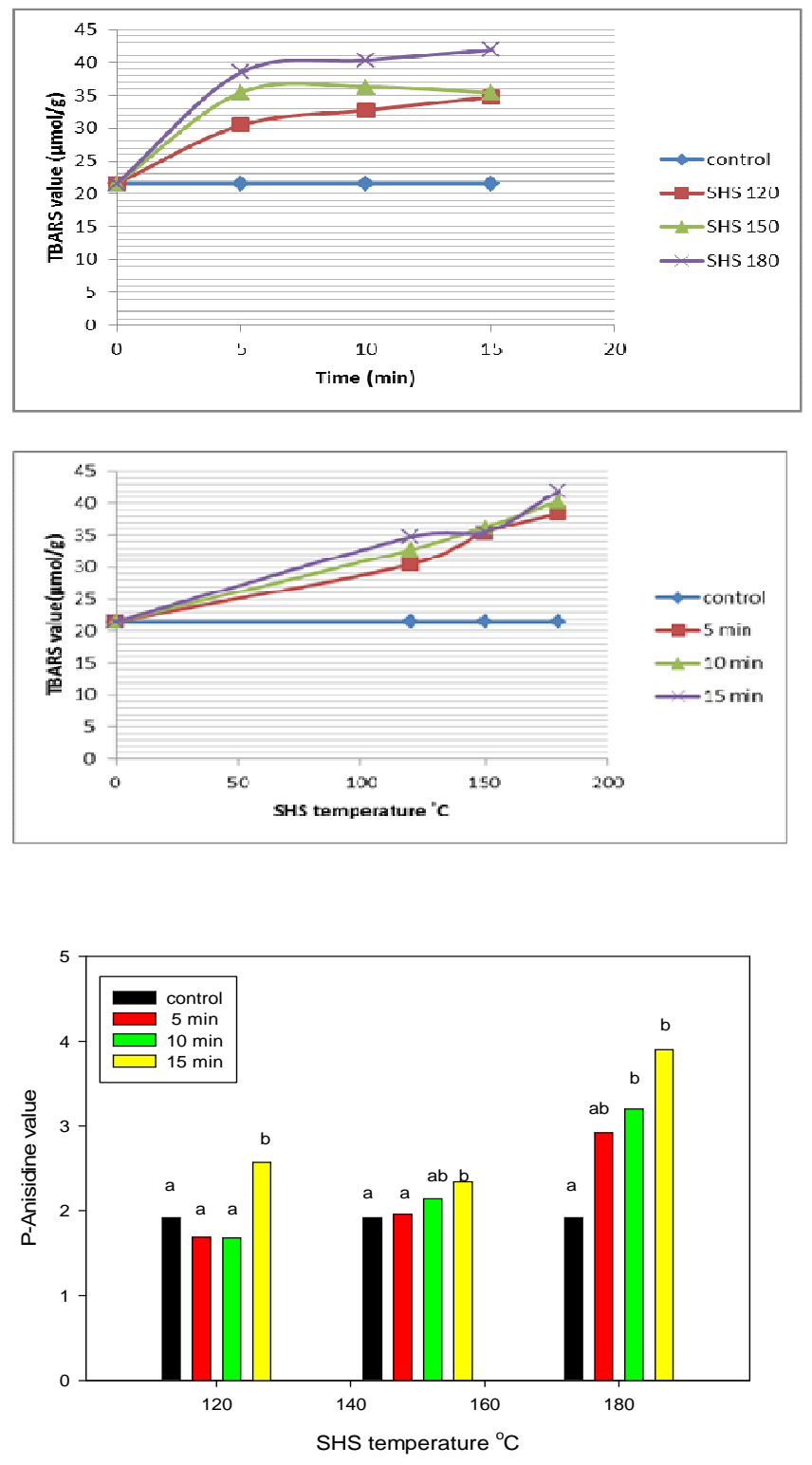

Fig 3: Effect superheated steam (temperature and time) on the TBARS values to reconstituted omega3-6 plus milk powder.

TBARS is measure secondary lipid oxidation by reacting TBA thiobarbituric acid with alkenals and alkadienals resulting from secondary oxidation specially from unsaturated fatty acids more than 3 double bounds to give term of also react thiobarbituric acid reactive substances (TBARS) [35].

The p-anisidine value ( $\mathrm{p}$-AnV) explain the secondary lipid oxidation, especially aldehydes principally 2-alkenals and 2,4-alkadienals produce by hydroperoxides in termination steps of oxidative mechanism [35]. Stability of P-anisidine value in reconstituted omega3-6 plus milk powder treated by superheated steam attributed to lack oxygen in SHS even prevent hydroperoxides formation resulting prevent aldehydes format [28].

Fig 4 show affects SHS temperatures and periods of time on the $\mathrm{P}$-anisidine value the result shows no significant differences at the $120-150{ }^{\circ} \mathrm{C}$ for 5-10 min compare with the control with some changes on the long time $15 \mathrm{~min}$ of 150
${ }^{\circ} \mathrm{C}$. At the high temperature $180{ }^{\circ} \mathrm{C}$ superheated steam present significant different compare with the SHS heat treatment and the control. All the results of P-anisidine have not much changed from the control (sample without heating) even after long time.

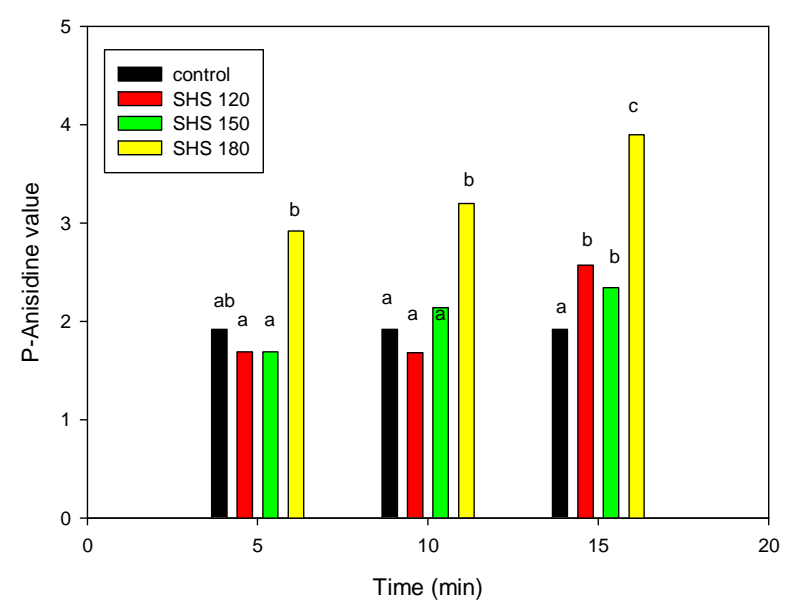

Fig4: Effect superheated steam (temperature and time) on the P-Anisidine value to reconstituted omega3-6 plus milk powder.

\section{CONCLUSIONS}

During heated reconstituted omega3-6 plus milk powder by superheated steam and indicated on changes in fatty acids and lipid oxidation by different methods of analysis. SHS temperature and time range used to indicate changes in milk fat. However, the superheated steam leads to decrease SFA content 179.73-169.13 mg. $\mathrm{g}^{-1}$ to maintain PUFA and MUFA from changes that explain no oxidation or degradation occur to the fatty acids during heat processing. Superheated steam show stability of lipid oxidation at different time and temperature with some changes of acid value, POV value, TBARS value and $\mathrm{P}$-anisidine value of the high temperature $180{ }^{\circ} \mathrm{C}$ and long-time $15 \mathrm{~min}$. By the results the temperature between $120-150{ }^{\circ} \mathrm{C}$ with periods of time 5-10 min present no significant differences on the changes in fatty acids or lipid oxidation that can be recommended to use this rang for treating milk or any product included milk by superheated steam.

\section{ACKNOWLEDGMENT}

Financial support for this study was provided by the School of Industrial Technology, Department of Food Technology, Universiti Sains Malaysia and support from the University of Tikrit, Tikrit Salah Al-Ddin Iraq.

\section{REFERENCES}

[1] Kolanowski W, Jaworska D, Weißbrodt J. Importance of instrumental and sensory analysis in the assessment of oxidative deterioration of omega-3 long-chain polyunsaturated fatty acid-rich foods, Journal of the Science of Food and Agriculture Vol, 87. PP,181-191. 2007.

[2] De Deckere EA. Health aspects of fish and n-3 polyunsaturated fatty acids from plant and marine origin. Nutritional Health Springer, pp. 195-206. 2001.

[3] Von Schacky C, Angerer P, Kothny W, Theisen K, Mudra H. The effect of dietary $\omega-3$ fatty acids on coronary atherosclerosisa 
randomized, double-blind, placebo-controlled trial. Annals of Internal Medicine, Vol. 130, PP. 554-562.1999

[4] Nash D, Hamilton R, Hulan H. The effect of dietary herring meal on the omega-3 fatty acid content of plasma and egg yolk lipids of laying hens. Canadian Journal of Animal Science, Vol. 75, PP. 247253.1995.

[5] Goodridge J, Ingalls J, Crow G. Transfer of omega-3 linolenic acid and linoleic acid to milk fat from flaxseed or Linola protected with formaldehyde. Canadian Journal of Animal Science, Vol. 81, PP. 525-532.2001.

[6] HMSO U. Nutritional aspects of cardiovascular disease. (report on health and social subjects No. 46.) London: HMSO; 1994.

[7] Trautwein E. n-3 Fatty acids—physiological and technical aspects for their use in food. European journal of lipid science and technology, Vol. 103, PP 45-55.2001

[8] Wallace J, McCabe A, Robson P, Keogh M, Murray C, Kelly P Marquez-Ruiz G, Mcglynn H, Gilmore WS and Strain JJ. Bioavailability of n-3 polyunsaturated fatty acids (PUFA) in foods enriched with microencapsulated fish oil. Annals of nutrition \& metabolism, Vol. 44, PP. 157-162.1999.

[9] Saldeen T, Wallin R, Marklinder I. Effects of a small dose of stable fish oil substituted for margarine in bread on plasma phospholipid fatty acids and serum triglycerides. Nutrition Research, Vol. 18, PP. 1483-1492.1998.

[10] Lovegrove J, Brooks C, Murphy M, Gould B, Williams C. Use of manufactured foods enriched with fish oils as a means of increasing long-chain n- 3 polyunsaturated fatty acid intake. British Journal of Nutrition, Vol.78, PP. 223-236.1997.

[11] Meshref A. Effect of heating treatments, processing methods and refrigerated storage of milk and some dairy products on lipids oxidation. Pakistan Journal of Nutritio, Vol. 7, PP. 118-125.2008.

[12] Mansson HL. Fatty acids in bovine milk fat. Food \& nutrition research, Vol. 52.2008

[13] Parodi PW. Milk fat in human nutrition. Australian Journal of Dairy Technology, Vol. 59, PP. 3-59.2004

[14] Jensen RG. The composition of bovine milk lipids: January 1995 to December 2000. Journal of Dairy Science, Vol.85, PP. 295350.2002 .

[15] Holub BJ. Clinical nutrition: 4. Omega-3 fatty acids in cardiovascular care. Canadian Medical Association Journal, Vol. 166, PP. 608615.2002

[16] Austin C, Smith TM, Bradman A, Hinde K, Joannes-Boyau R, Bishop D, Dominic J, Philip D, Brenda E and Manish A. Barium distributions in teeth reveal early-life dietary transitions in primates. Nature, Vol. 498, PP. 216-219.2013.

[17] Arab-Tehrany E, Jacquot M, Gaiani C, Imran M, Desobry S, Linder M. Beneficial effects and oxidative stability of omega-3 long-chain polyunsaturated fatty acids. Trends in Food Science \& Technology, Vol. 25, PP. 24-33.2012.

[18] Cocup R, Sanderson W. Functionality of dairy ingredients in bakery products. Food technology (USA) 1987.

[19] Gardner HW. Oxygen radical chemistry of polyunsaturated fatty acids. Free Radical Biology and Medicine, Vol. 7, PP. 65-86.1989.
[20] ZZaMan W, Yang TA. Effect of superheated steam and convection roasting on changes in physical properties of cocoa bean (Theobroma cacao). Food Science and Technology Research, vol. 19, PP. 181186.2013.

[21] Pronyk C, Cenkowski S, Muir W. Drying foodstuffs with superheated steam. Drying Technology, Vol. 22, PP. 899-916.2004.

[22] Abdulhameed AA, Zzaman W, Yang TA. Application of Superheated Steam in Sample Preparation (Chicken Sausage) for Determination of Total Fat, Fatty Acid and Lipid Oxidation. Food Science and Technology, vol. 2, PP. 27-33. 2014.

[23] Nielsen S. Food analysis laboratory manual. Springer Science \& Business Media; 2010.

[24] Simionato JI, Garcia JC, Santos GTd, Oliveira CC, Visentainer JV, Souza NEd. Validation of the determination of fatty acids in milk by gas chromatography. Journal of the Brazilian Chemical Society, Vol. 21, PP. 520-524.2010

[25] Atinafu DG, Bedemo B. Estimation of total free fatty acid and cholesterol content in some commercial edible oils in Ethiopia, Bahir DAR. Journal Cereals Oilseeds, vol. 2, PP. 71-76. 2011.

[26] Tompkins C, Perkins EG. The evaluation of frying oils with the panisidine value. Journal of the American Oil Chemists Society, Vol. 76, PP.945-947.1999.

[27] Raksakantong P, Siriamornpun S, Meeso N. Effect of drying methods on volatile compounds, fatty acids and antioxidant property of Thai kaffir lime (Citrus hystrix DC). International journal of food science \& technology, Vol.47, PP. 603-612. 2012.

[28] Mahdy G, Yang TA. Effect of superheated steam on lipid oxidation of reconstituted whole milk powder. International Journal of Scientific \& Engineering Research, vol 5.pp,250-256,Oct. 2014.

[29] Mahdy G, Yang TA. Changes in Fatty Acid Composition of Reconstituted Whole Milk Powder by Superheated Steam. World Journal of Dairy \& Food Sciences, Vol 9. PP, 250-259,2014.

[30] Albi T, Lanzón A, Guinda A, León M, Pérez-Camino M. Microwave and conventional heating effects on thermoxidative degradation of edible fats. Journal of agricultural and food chemistry, Vol. 45, PP. 3795-3798.1997.

[31] Tzou-Chi Huang, Chi-Tang Ho and Hui-Yin Fu. Inhibition of lipid oxidation in pork bundles processing by superheated steam frying. Journal of agricultural and food chemistry, Vol. 52, PP. 2924-2928. 2004

[32] Dey S, Karim M. study on physicochemical and microbial quality of available raw, pasteurized and uht milk during preservation.International journal of scinence inventions today, vol.2, PP.150-157, Apr. 2013.

[33] Cilliers FP, Gouws PA, Koutchma T, Engelbrecht Y, Adriaanse C, Swart P. A microbiological, biochemical and sensory characterisation of bovine milk treated by heat and ultraviolet (UV) light for manufacturing Cheddar cheese. Innovative Food Science \& Emerging Technologies, Vol. 23, PP. 94-106.2014.

[34] Aladedunye AF. Inhibiting thermo-oxidative degradation of oils during frying. Lethbridge, Alta.: University of Lethbridge, Dept. of Chemistry and Biochemistry, 2011.

[35] Shahidi F, Zhong Y. Lipid oxidation: measurement methods. Bailey's industrial oil and fat products 2005. 